Editorial

\title{
Translation as the Catalyst of Cultural Transfer
}

\author{
Albrecht Classen \\ Department of German Studies, 301 LSB, University of Arizona, Tucson, AZ 85721, USA; \\ E-Mail: aclassen@email.arizona.edu
}

Received: 14 March 2012 / Accepted: 26 March 2012 / Published: 30 March 2012

\begin{abstract}
This essay reflects on the many different strategies involved in translation, which is both a linguistic and a cultural-historical strategy. Examples from the Middle Ages and the Modern Age are adduced to illustrate the huge impact which translations have had on peoples and societies throughout time.
\end{abstract}

Keywords: translation; translation theory; cultural impact of translations; translations as cultural ambassadors; political and ideological impact of translations; translations in the Humanities

\section{Introduction: Humanities, Languages, and Translation}

The Humanities would be a very impoverished field of academic inquiry if we were all limited to the use of one language and one culture only. After all, to focus just on one tiny language by itself, the change over time transforms every language, making translation to a critically important task for anyone interested in the history of human life, activities, culture, and literature. Every human being can and does contribute to the constant growth of our culture, and the more different voices get involved in that discourse, the richer the result promises to be. At all times and all over the world people have developed into separate groups and hence have acquired or developed different languages. Language itself is an organic and constantly changing phenomenon, whether we consider the larger family groups, national languages, dialects, jargons, Pidgin, or Creole. Language, however we might define it (including signs, images, and generic sounds), reflects on and determines human culture, personal experiences, learning, religion, values, ideologies, and the like.

To be sure, the more languages or dialects an individual commands, the wider his or her mental horizon expands, and the richer proves to be his or her cultural background. We grow as human beings not only in material terms, but, naturally, also, and above all, by the acquisition of knowledge, of understanding at large, of the ability to handle certain operations and tools, and, finally, we grow by a 
ever new comprehension of ideas, concepts, arguments, logical deductions, conclusions, but then also by the realization of feelings, sentiments, attitudes, and values. My emphasis on 'value' does not come by happenstance because values define cultures and hence all of human life. Wars are fought, among many other reasons, over differences in values, since they lead to different interpretations of this world. Of course, in the ultimate analysis, the real reasons can be broken down into greed, fear, and lust for power, all typical human weaknesses which the Catholic Church has identified, in an expanded spectrum, as the 'Seven Deadly Sins.' Tragically, if the communication is lacking between two sides, they tend to ignore the most likely consequences of any war for both sides, mutual destruction, or at least devastation and wide-spread poverty and misery.

\section{Miscommunication and Translation: Past and Present}

A good example would be the medieval Crusades which were certainly driven by deep religious ideals, and yet were also determined by imperialist, colonialist, and military goals. From our perspective today, however, especially in the wake of $9 / 11$, all crusade propaganda has worked only because both sides of the military conflict have not been able or willing to develop a mutually understandable language or a mutually shared paradigm of values, such as the sacredness of human life. The incredibly productive counter example, which had a universal impact as well and promoted an amazing growth in scientific and philosophical knowledge in medieval Europe, was the broad-ranging translation process that took place at the universities of Toledo, Spain, and Salerno, Italy, during the twelfth century. A large number of Arabic texts were finally translated into Hebrew, and from there into Latin. From that point on they were all widely available all over Europe and were richly disseminated, soon also translated into the various vernaculars [1,2]. The reason for the great interest by the European intellectuals, scientists, theologians, and philosophers was that the Arabs had preserved more than anyone else in the western world the ancient Greek texts by such great minds as Aristotle and Galen, but in Arabic translation. When those texts finally became available in European languages, this led to a major innovation and transformation of all intellectual enterprises, which we call today the Renaissance of the Twelfth Century [3].

\section{The Problematics of Translation: Past and Present}

What does translation really mean? There is the literal translation and the metaphorical one. One can translate literally by rendering a text from one language into another language, relying on a variety of strategies, either trying to stay very close to the original, almost transposing it into the new language word by word, or by providing more or less of the essential meaning and the sense, paying critical attention to the appropriateness of the idiomatic expressions and conceptual approaches. Martin Luther's great contribution to Western culture consisted really in his efforts to return to the ancient Greek sources of the New Testament (1522) and to translate those not the way how the Vulgate had been translated over centuries (Jerome), but to translate the sacred texts in a meaningful way, making them understandable and accessible for the ordinary reader [4]

One can also translate metaphorically by explaining one phenomenon in culture $\mathrm{x}$ by transferring or correlating it to a parallel phenomenon in culture y. One can translate mechanically by resorting to a pedestrian, ordinary, or run-off-the-mill strategy, without any concern for aesthetics, structures, or 
formal criteria that defined the original. One can also translate in quite a different manner by making one culture understandable to another, and help one people on the other side of the border comprehend the other without necessarily resorting to language per se. One would not really need many linguistic skills in the last approach to translation, and could achieve the desired goal simply by showing pictures, playing music, gesturing, mimicking, and the like. Sharing food, for instance, or going for a walk together could be an intriguing type of translation, and translation thus emerges as a strategy both to understand the other side and to gain a sense of the own self [5].

There are other dimensions of translation as well. Many times we need to translate texts or speeches from one social level to another, from a scientific perspective to an ordinary plateau. Then we often have to translate from a dialect text to a standard language text, and vice versa. Ultimately, all interpretations and analyses prove to be translations as well because the critical reader transposes the meaning hidden in a text, in a musical composition, a sculpture, a building, or an image into a comprehensible form, unfolding and explicating the specific points inscribed in the object of analysis.

Translation happens every day, in every speech act, in every exchange between people, whether in a face-to-face situation or virtually/digitally, and yet, as we all know only too well, the possibilities of misunderstandings, misreadings, and miscommunicating are endless [6]. Good translators, in concrete, linguistic terms and also those who work in social and political fields connecting with other people and languages, are constantly aware of the enormous need to revise their work, to double-check, to verify, and thus to return to the original, which tends to defy all attempts to render it properly or completely into the other language. In this regard, translation can be identified as a metaphor of all human activities since we are social beings and heavily rely all the time on the ability to collaborate and to communicate with each other, whatever language we might speak [7].

\section{The Cultural-Historical Impact of Translations}

To return briefly to my previous thought, most military conflicts in this world could be determined as being the result of the break-down, the failure of, or the inability of those involved in developing a proper communication. Ironically, not even sharing the same language helps us necessarily to avoid the most basic conflicts because very few people are sensitive or trained well enough to be good translators. In other words, translation is not only a technical transfer from one language to another, but, on a much larger scale, a transfer from one culture to another, building enormously important bridges that connect people from all over the world with each other [8,9]. Translation also means to comprehend the statements of one person in his or her social and political contexts and to render those meaningful in another context. Not surprisingly, neither men nor women can easily translate what the other one is truly saying, although they do not necessarily face any linguistic problems.

As the history of Western culture and literature, for example, illustrates, every new introduction of texts from other languages has regularly resulted in major innovations, whether we think of the so-called 'Carolingian Renaissance', the above-mentioned 'Renaissance of the Twelfth Century,' the Protestant Reformation, the Enlightenment, or the American Renaissance. Little wonder that many of the most penetrating thinkers over time have turned their full attention to the issue of proper translation and the meaning of translation at large, whether we think of Friedrich Schleiermacher [10], Walter Benjamin [11], or Jacques Derrida [12]. After all, translating is both a concrete, difficult, and 
challenging linguistic task and also a profound philosophical, ethical, moral, religious, and political operation of larger and smaller proportions.

From that perspective translation itself quickly leads to transcultural activities since making ideas, thoughts, concepts, and texts, for instance, available to people across a linguistic and cultural divide certainly lowers that very divide and establishes powerful connections and allows individuals from both worlds to approach each other and to enter new cultural communities that have not existed beforehand $[13,14]$. The more we are empowered to translate, the more we have the chance to improve the social construct of our own world or society in close collaboration with neighbors and the natural environment, as the example of the European Union illustrates at the moment so impressively.

\section{Translation in the Middle Ages as a Model Case}

Already the Middle Ages witnessed many attempts of reaching out to other cultures and languages, of learning from neighboring countries, cultures, and people, and to integrate new ideas and values from worlds beyond their own [15]. Although major, 'national,' languages had emerged already in the eighth century, huge dialect differences dominated the entire era far into the sixteenth century [16]. Of course, dialects have not disappeared until the very present, but they assume a different sociological function today than in the past and are more subordinated than ever before. This, however, does not make them more easily understandable, on the contrary, and we continue to rely on translations, here understood in its widest possible connotations, to communicate between the standard language and the dialect. In this regard every translation constitutes an effort to build more intimate connections between people of different cultures, languages, religions, and ideals [10].

This linguistic complexity in the Middle Ages might come as a surprise for many modernists who have only the history of the Crusades, for example, and the many pogroms against Jews in mind when they consider that premodern period. Insofar, however, as already many medieval intellectuals were deeply invested in translating, both from Latin into the various vernaculars, and from Arabic into Hebrew and then into Latin, we can easily recognize the continuous and irresistible allure of translations as the critical vehicles for the flow of ideas [17]. We do not yet know enough about the translation efforts connecting the various vernacular literatures, although we can be certain that there were many channels between the French-, German-, Scandinavian-, or Italian-speaking language areas.

Translators and translations throughout time have had a huge impact on people, social groups, communities, and nations, whether we think of missionaries from the time of Ulfila among the Goths (fourth century) to the Anglo-Saxon Benedictine monks in Frankish Germany (eighth century), or to the Jesuit missionaries in the Americas (sixteenth century to 1767), or whether we consider poets, philosophers, and linguists who have constantly made great efforts to provide access to texts in other languages [18]. Language barriers have always existed, and they continue to represent huge challenges until today.

\section{The Linguistic Situation Today and Translation}

Although we now often hear of the so-called "Global Village," this does not mean at all that all people would understand each other easily, if at all, or that the mythical "Tower of Babel" has finally been overcome in the twenty-first century. The use of Latin throughout the Middle Ages might have 
been the closest approximation to that ideal, but the vernaculars retained their central role and ultimately dominated even public, administrative discourses, erecting significant barriers to other linguistic groups on the outside. The Catholic Church has remained the only surviving institution on a global level utilizing Latin as its lingua franca, defying all modern trends to submit to French or English as the new global languages.

Certainly, conference English is nowadays widely used, as poorly as it might sound in grammatical or lexical terms [19] Technical information can now commonly be fairly easily distributed and shared on a global level, but this does not mean at all that the specific points of culture, of values and ideals, of religious concepts and political viewpoints have thus become more easily translatable or are simply shared across cultural borders. Software engineers and computer programmers are working assiduously at finding ways to utilize the internet as the medium for instant translations of texts. Nevertheless, the problems in those areas continue to represent huge hurdles, and practical and easy solutions still seem to be far out of our reach [20]. Of course, a technical translation might serve well the primary purpose of making basic information available. However, the need for in-depth translation sensitive to cultural, linguistic, political, ethical, or moral aspects mostly resists mechanical operations [21], although constant progress in that area can probably not be denied. We can identify some of the critical problems as how to handle nuances in meaning, idiomatic expressions, value concepts, idiosyncratic formulations, poetic and metric structures, etc. Some of the most problematic areas prove to be political treatises because they hinge so much on very specific points that easily defy a simple translation. But bad or misleading translations can have catastrophic consequences for entire peoples, for the environment, and for mankind.

\section{Translation and the Humanities}

In short, then, translation represents a truly humanistic task and requires a host of specialists of different expertises to come together to achieve the desired goal. The linguist and the literary scholar, for instance, depend on each other for a full comprehension of both the original text and the translated version, as the collaboration of the Germanist Alan Keele and the Welsh poet Leslie Norris illustrates so beautifully, who achieved their task of translating Rilke's Sonnets to Orpheus to the fullest possible extent only because of their teamwork [22,23]. A good translator demonstrates a deep understanding of two cultures, their historical developments, their ideological and political frameworks, their traditions, religions, etc. In practical terms, this really implies that the study of translation must be based both on an intensive acquisition of the language and on the understanding of the culture of the target group. Otherwise, all efforts of creating a good translation will remain elusive, piecemeal, superficial, and inadequate.

On the other hand, a successful translator does not only make an original piece available in another language (and this both in literal and metaphorical terms), but s/he also builds enormously important practical bridges between cultures, peoples, values, and ideas. That is, in essence, the fundamental task of the Humanities. The specific, technical translation from one language to the other is only one, though certainly important dimension in this larger project. More globally speaking, however, translation from one culture to the other addresses much larger issues, spreading ideas and values from one society to another society. 
'Translations in that context can suddenly assume an almost dangerous, explosive function because they offer new perspectives and invite people to experiment with alternatives to the system they are familiar with. Luther's Bible translation was a great example for that phenomenon, such as the countless translations of Karl Marx's and Friedrich Engel's Communist Manifest since its first publication in 1848 and of many others of their writings deeply influenced the history of the entire world ever since (Socialism). In the present day and age, by means of the internet, innumerable texts are constantly translated and hence made available to an ever growing global audience, but we can safely assume that until the present translation machines have matched, if they ever will, the skill represented by a human translator, the task to work on appropriate translations will continue to be a central challenge for all of society.

Moreover, translations from medieval literature, Dante Alighieri's Divina Commedia (1308-1321), for instance, especially since its rediscovery in the eighteenth century (the Inferno was first translated by Henry Boyed in 1785), have also deeply impacted and inspired whole generations of writers and artists until the present [24], transforming their outlook and understanding of their own world. The entire movement of Romanticism, in many respects brought to life through the rediscovery of the Middle Ages, could not be imagined without a strong efforts by many philologists to translate for the first time in modernity medieval texts into their own vernaculars. In other words, translation implies considerably more than just a mechanical process. Instead, true translations transport ideas and break down linguistic, cultural, ethnic, and ideological barriers, and they carry the potential of radically influencing whole societies and their political and economic structures, not to speak of religious systems (missionary work!). In the Humanities, where we teach the necessary skills to comprehend foreign cultures and languages, we create the bedrock from which translations can be launched, which then can exert a huge impact on people and society at large. Keeping this in mind, we have to realize the enormous outreach and influence capacities inherent in the Humanities because that is the very space within the Academy where the cultural, linguistic, ethnic, and philosophical pioneers, scholars, and practioners are trained whose task it is to establish contacts with other people, other languages, and thus to connect people in a global network.

\section{Conclusion: The Study of Foreign Languages and the Humanities}

However, despite everything one can put forth in favor of translations, we would badly misunderstand the ultimate purpose of all our work in the Humanities if we completely relied on translations. After all, a translation is only the second to the best, and can never fully substitute the study of the original. The translation can nicely support our efforts to build connections and to establish familiarity and comprehension, while the true purpose must really be to acquire the specific foreign language skills and to read the original texts in their own language. Of course, for most, if not all, people, it proves to be impossible to study enough foreign language to understand exhaustively or comprehensively the original source. Nevertheless, we must always strive for the ideal to learn as much of the foreign language as possible in order to make a solid case for our interpretative conclusions. By contrast, anyone who entirely relies on translations becomes the helpless victim of the translator, as good as s/he might be. After all, every translation proves to be only an approximation and can never fully substitute for the original. 
In practice, of course, translations are of highest value in the interaction with a multilingual world since our language skills are, even in the best-case scenario, limited to three, four, or five foreign languages [25]. Comparative literature, cultural studies, or comparative religions certainly profit highly from the existence of translations, but we must never forget that the translation only constitutes an interpretative attempt and will never completely allow the full access to the messages, ideas, values, or concept contained in the original document or object under investigation.

Of course, can we actually ever claim to be in total command of our own mother tongue, or are we not always drawing from a variety of linguistic registers, dabbling around in a multilingual potpourri? Any dialect speaker would confirm the extent to which the individual easily thrives from the knowledge of at least two languages. In this regard, especially if we also add the observation that people are migrating all over globe more than ever before, we can conclude that multilingualism on a much broader level is alive and well all [26,27], which makes translation more important than ever before. To make all their living conditions better and to help modern societies to cope with the constantly growing mixing of different languages, translation emerges as a critical tool both on the purely linguistic and on the cultural level, as long as we never forget that the original text still carries the greatest validity, being prime in its authenticity.

\section{References and Notes}

1. Speer, Andreas, and Lydia Wegener, Eds. Wissen über Grenzen: arabisches Wissen und lateinisches Mittelalter. Miscellanea Mediaevalia, 33. Berlin and New York: de Gruyter, 2006.

2. Lejbowicz, Max, and Monique Bourin, Eds. Une conquête des savoirs: les traductions dans l'Europe latine (fin XIe siècle-milieu XIIIe siècle). Turnhout: Brepols, 2009.

3. Constable, Giles. The Reformation of the Twelfth Century. Cambridge: Cambridge University Press, 1996.

4. Gelhaus, Hermann. Der Streit um Luthers Bibelverdeutschung im 16. und 17. Jahrhundert. Reihe Germanistische Linguistik, 89. Tübingen: Niemeyer, 1989.

5. Sakai, Naoki. "Translation and the Figure of Border." Profession 2010 [MLA], 25-34.

6. Steiner, George. Language and Silence: Essays on Language, Literature, and the Inhuman. New York: Atheneum, 1967.

7. Parra Membrives, Eva, Miguel Ángel García Peinado, and Albrecht Classen, Eds. Aspects of Literary Translation. Tübingen: Narr, 2012.

8. Graham, Joseph F., Ed. Difference in Translation. Ithaca, NY, and London: Cornell University Press, 1985.

9. Apter, Emily S. The Translation Zone: A New Comparative Literature. Princeton: Princeton University Press, 2006.

10. Schleiermacher, Friedrich. "Ueber die verschiedenen Methoden des Uebersetzens." 1813, http://users.unimi.it/dililefi/costazza/programmi/2006-07/Schleiermacher.pdf (last accessed on 5 March 2012).

11. Benjamin, Walter. "Die Aufgabe des Übersetzens." In Gesammelte Schriften. Edited by Rolf Tiedemann und Hermann Schweppenhäuser. Frankfurt a. M.: Suhrkamp, 1972, vol. 4.1, pp. 9-21

12. Derrida, Jacques. "Des tours de Babel." Psyché: Inventions de l'autre 1998, I, 203-35. 
13. Sandkühler, Hans Jörg, and Hong-Bin Lim, Eds. Transculturality: Epistemology, Ethics, and Politics, Philosophie und Geschichte der Wissenschaften, 57. Frankfurt a. M., Berlin, et al.: Peter Lang, 2004.

14. Martinson, Steven, and Renate Schulz, Eds. "Transcultural German Studies: Building Bridges.” In Jahrbuch für Internationale Germanistik, A, 94. Bern, Berlin, et al.: Peter Lang, 2008.

15. Knoblauch, Hubert, and Helga Kotthoff., Eds. Verbal Art Across Cultures: The Aesthetics and Proto-Aesthetics of Communication. Literatur und Anthropologie, 10. Tübingen: Narr, 2001.

16. Schnell, Rüdiger. "Vom Nicht- und Missverstehen im Mittelalter: Zu Hindernissen sprachlicher und nicht-sprachlicher Interaktion." In Zwischen Babel und Pfingsten: Sprachdifferenzen und Gesprächsverständigung in der Vormoderne (8.-16. Jahrhundert). Ed. by Peter von Moos. Vienna. Zürich, and Berlin: LIT Verlag, 2008, 567-90.

17. Hundsbichler, Helmut. Ed. Kommunikation zwischen Orient und Okzident: Alltag und Sachkultur. Vienna: Verlag der Österreichischen Akademie der Wissenschaften, 1994.

18. Delisle, Jean, and Judith Woodsworth, Eds. Translators Through History. Benjamins Translation Library, 13. Amsterdam and Philadelphia: John Benjamins, 1995.

19. Gnutzmann, Claus, and Frauke Intemann, Eds. The Globalisation of English and the English Language Classroom. Tübingen: Narr, 2008.

20. For a complex discussion, see the contributions to the online journal The International Journal of Translation and Interpreting Research.

21. Danet, Brenda, and Susan C. Herring, Eds. The Multilingual Internet: Language, Culture, and Communication Online. Oxford: Oxford University Press, 2007.

22. Rilke, Rainer M. The Sonnets to Orpheus. Translated by Leslie Norris and Alan Keele. Columbia, SC: Camden House, 1989.

23. Rilke, Rainer M. The Duino Elegies. Translated by Leslie Norris and Alan Keele. Columbia, SC: Camden House, 1993.

24. Ley, Klaus, Ed. Dante Alighieri und sein Werk in Literatur, Musik und Kunst bis zur Postmoderne, Mainzer Forschungen zu Drama und Theater, 43. Tübingen: Francke, 2010.

25. Edwards, John R. Multilingualism: Understanding Linguistic Diversity. London: Continuum, 2012.

26. Weber, Jean-Jacques, and Kristine Horner, Eds. Introducing Multilingualism: A Social Approach. New York: Routledge, 2012.

27. Yildiz, Yasemin. Beyond the Mother Tongue: The Postmonolingual Condition. New York: Fordham University Press, 2012.

(C) 2012 by the author; licensee MDPI, Basel, Switzerland. This article is an open access article distributed under the terms and conditions of the Creative Commons Attribution license (http://creativecommons.org/licenses/by/3.0/). 